\title{
Study on physical model of the crossing of the Rhône flood plain by a new railway line near Lyon
}

\author{
Sébastien Derrien ${ }^{1, a}$, Claude Guilbaud ${ }^{1}$, Yves Simond $^{2}$ and Denis Cuvillier ${ }^{2}$ \\ ${ }^{1}$ ARTELIA Eau \& Environnement, 6 Rue de Lorraine, 38130 Echirolles, France \\ ${ }^{2}$ SNCF Réseau, 78 Rue de la Villette, 69425 Lyon Cedex 3, France
}

\begin{abstract}
In order to address the questions raised by a new railway line crossing the Rhône, and in addition to mathematical modelling conducted during the preliminary studies, SNCF Réseau commissioned Artelia Eau \& Environnement with a physical scale model study of the projected infrastructure. The physical scale model represented the river Rhône and its flood plain, the existing bridges over the river Rhône for the A432 motorway and the high speed line, and then the project (viaduct and relief structures). After calibration of the measurements devices, tests were carried out in current conditions, in design conditions and in optimised design conditions. The physical scale model enabled to identify the hydraulic impact of the project during flood events (increase of the maximum water level, due to bad flow conditions at the inlet of relief structures) and validate the improvements of the design (reshaping of the relief structures' inlet, and removal of embankments close to the relief structures). The final optimized design ensures the hydraulic transparency of the project.
\end{abstract}

\section{Introduction}

The project of rail by-pass around Lyon urban area (CFAL - Contournement Ferroviaire de l'Agglomération Lyonnaise) is led by SNCF Réseau (former Réseau Ferré de France). This project is strategic at regional, national and European scale: it is planned both for the movement of passenger trains and freight, it will improve the rail network while freeing up capacity at the heart of the Lyon railway junction, and it will promote economic dynamics in the Rhône-Alpes region.

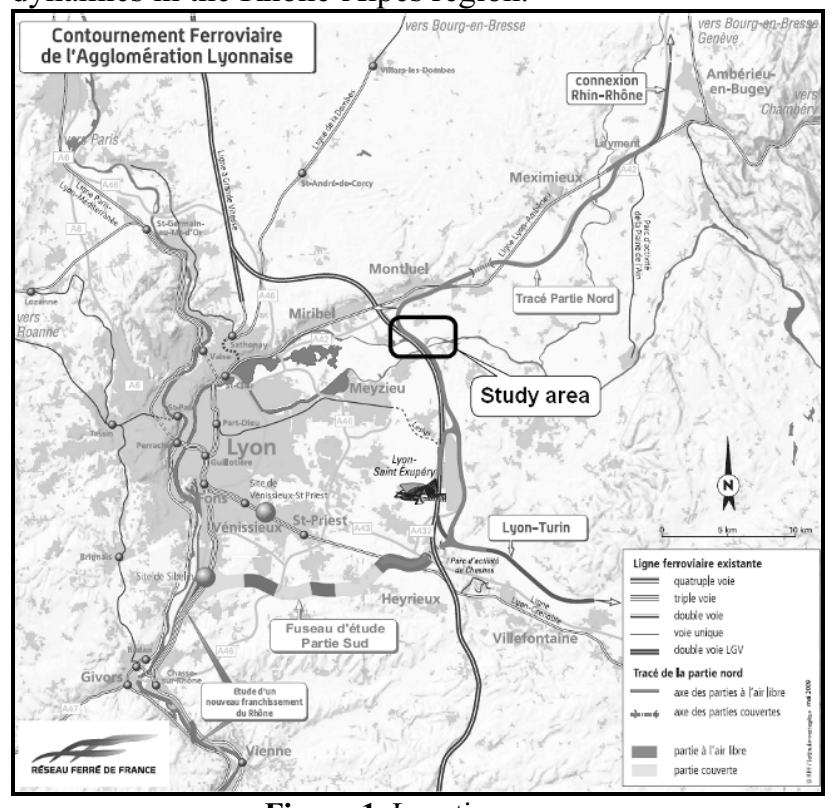

Figure 1. Location map

$\overline{{ }^{a} \text { Corresponding author: sebastien.derrien@arteliagroup.com }}$
In order to address the questions raised by the project at the crossing of the Rhône in its northern branch, and in addition to mathematical modelling conducted during the preliminary studies, SNCF Réseau commissioned Artelia Eau \& Environnement with a physical scale model study of the bridge over the river Rhone for the new railway line, located at the end of Miribel Jonage island and close to the town of Nievroz, which is exposed to floods.

The objectives of the physical scale model study were the following:

- characterisation of the hydraulic impact (qualitative \& quantitative) of projected structures on flood discharges and flow conditions;

- optimisation of structures and of constructional requirements in order to minimise these impacts.

\section{The scale model}

\subsection{Similitude and scale factor}

The flows being free surface ones, the study on scale model is conducted using Froude's similitude, i.e. Froude's number (ratio between inertia and gravity forces) is the same on the model and in nature.

The Froude's number is given by the following formula:

$$
F r=v / \sqrt{ }(g h)
$$


with:

- v: velocity $(\mathrm{m} / \mathrm{s})$

- g: gravity acceleration $\left(\mathrm{m} / \mathrm{s}^{2}\right)$,

- $\quad$ h: flow depth (m),

According to the problems to be studied and the size of the project, the geometrical scale factor $(\lambda)$ is $1 / 80$. This scale allows for the representation in the model of the maximum flows and is appropriate for the study of the hydraulic impact of projected structures. The model is undistorted (same vertical and horizontal scales).

Considering the Froude similitude is achieved, the scale factors are the following:

- water levels: $\lambda_{\mathrm{h}}=\lambda=1 / 80$

- velocities: $\lambda_{\mathrm{v}}=\lambda^{1 / 2}=1 / 8.9$

- $\quad$ discharge: $\lambda_{\mathrm{Q}}=\lambda^{5 / 2}=1 / 57243$

- $\quad$ time : $\lambda_{\mathrm{t}}=\lambda_{\mathrm{t}}=\lambda^{1 / 2}=1 / 8.9$

\subsection{Model extent}

The physical scale model represents the river Rhône and its flood plain (including the town of Nievroz), the existing bridges over the river Rhône for the A432 motorway and the high speed line, and then the CFAL project (viaduct and relief structures).

The model represents $4 \mathrm{~km}$ of the Rhône river $(50 \mathrm{~m}$ on model) and covers an area of $5.2 \mathrm{~km}^{2}$ (approximately $800 \mathrm{~m}^{2}$ on model).

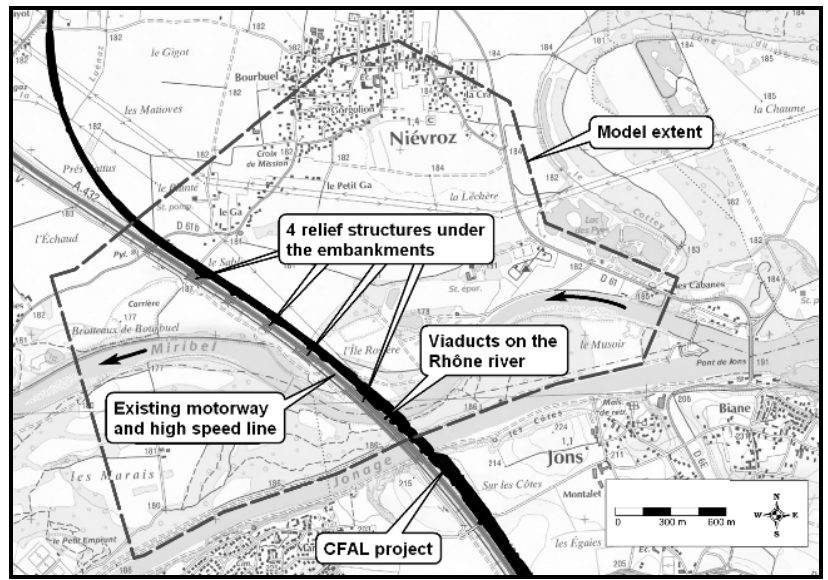

Figure 2. Model extent

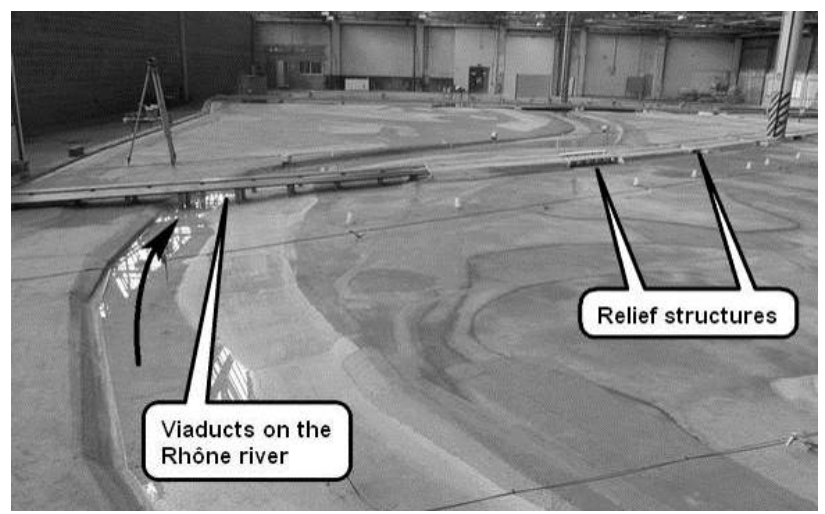

Figure 3. General upstream view of the model

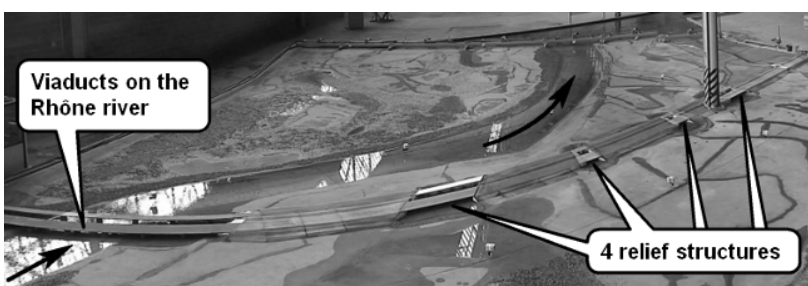

Figure 4. General top view of the model

\subsection{Model equipment}

In order to accurately reproduce unsteady flow conditions in the Rhône large flood plain area, the following equipment layout is set up on the model:

- for inflow control: discharge-controlled pump with electromagnetic flow meter,

- for outflow control: downstream level controlled by four flap gates across the flood plain, reproducing the various water levels calculated by a previous numerical model study,

- for water level measurement: continuous measurement and recording by 22 calibrated ultrasound sensors, distributed within main channel and flood plain,

- for flow velocity measurement: micro propeller inside the structures (viaduct and relief structures), and a LS-PIV (Large Scale Particle Image Velocimetry) system combined with a data processing software,

- for maximum flood expanse survey: robotic survey station,

- for general flow patterns visualisation: use of dye injected from 10 points underneath the ground level.

All electronic equipment (flow meters, flap gates, ultrasound sensors, camera for LS-PIV recording) is monitored and operated from a unique computer workstation with dedicated controlling software, specially developed for the purpose of the model study.

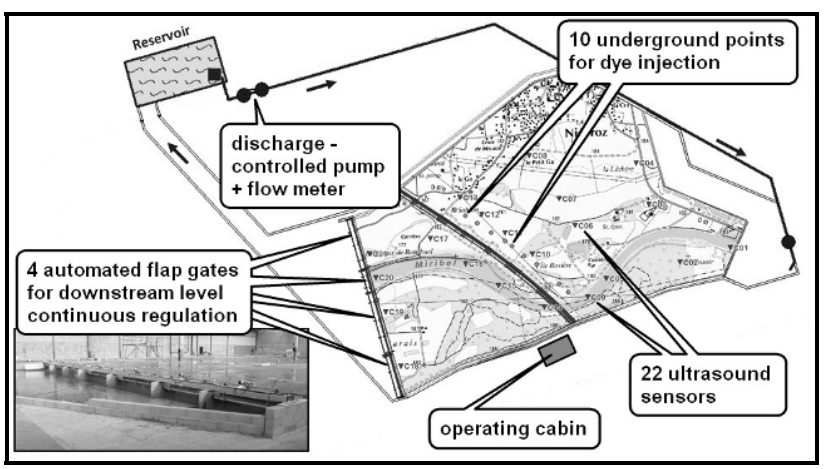

Figure 5. General view of the model equipment 


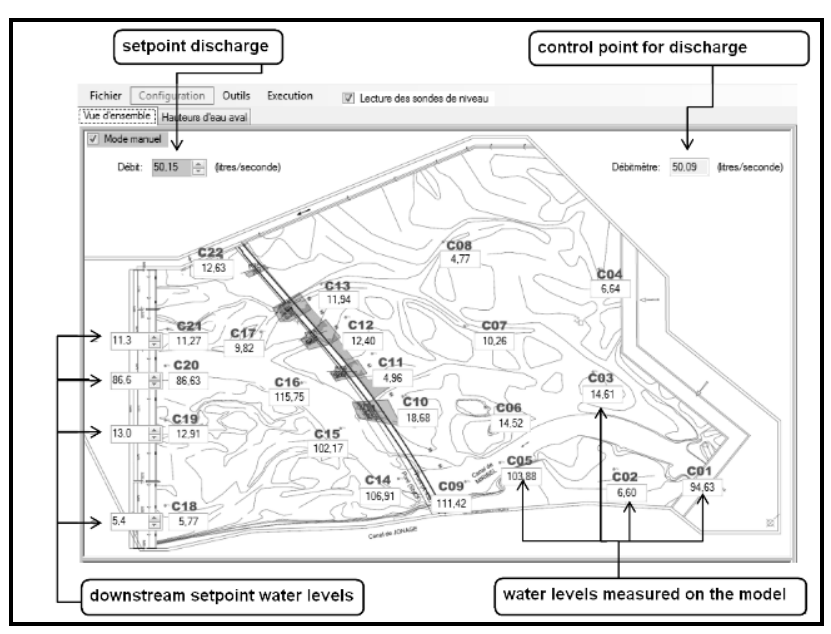

Figure 6. General view of the controlling software

\section{Model tests}

\subsection{Calibration tests}

After calibration of the measurements devices, a first series of tests is carried out in order to calibrate the scale model and ensure that it reproduces correctly natural phenomena.

The calibration is a two-stage procedure:

- simulation of non-overflowing conditions and comparison with recorded water levels in the river. This first step leads to calibrate the river bed roughness, with an average difference in water levels of $10 \mathrm{~cm}$ nature.

- simulation of the 1990 overflowing flood (30years event) and comparison with recorded water levels in the river, surveyed maximum flood extent and results of the previous numerical model (maximum water level in the flood plain and development of the unsteady flooding process). This second step leads to calibrate the flood plain roughness in the vegetalised areas, as realistically as possible. The average difference in water levels is $12 \mathrm{~cm}$ in the main channel compared to recorded water levels, and $10 \mathrm{~cm}$ in flood plain compared to numerical modelling. Except in one area where the topography is very flat and therefore sensitive to a small water level variation, the maximum flood extent is very well reproduced. Compared to numerical simulations, the overflowing process occurs sooner and more progressively on the physical model, but the general shape of the water rise and the maximum water levels during flood peak are similar.

\subsection{Tests conditions}

Tests are carried out under the following conditions:

- 100-year flood

- 1,000 -year flood
- Unsteady flow for flooding process, recording of water levels variations and maximum flood extent,

- Steady flow at peak discharge for velocity measurements (by micro propeller and LS-PIV), flow patterns identification (by use of dye) and checking of the maximum flood extent.

\subsection{Tests in current conditions}

By comparison with numerical simulations, the physical model enables to:

- confirm the maximum flood extent and maximum water levels,

- precise the hydraulic functioning of the relief structures under the existing motorway and high speed line, as they are explicitly modelled. Flow patterns and flow velocities in front and through the structures are fully described. Measurements show that the flow in the flood plain is slightly higher $(+10 \%)$ for both tested discharges on the scale model, but the global flow repartition within the four relief structures is confirmed.

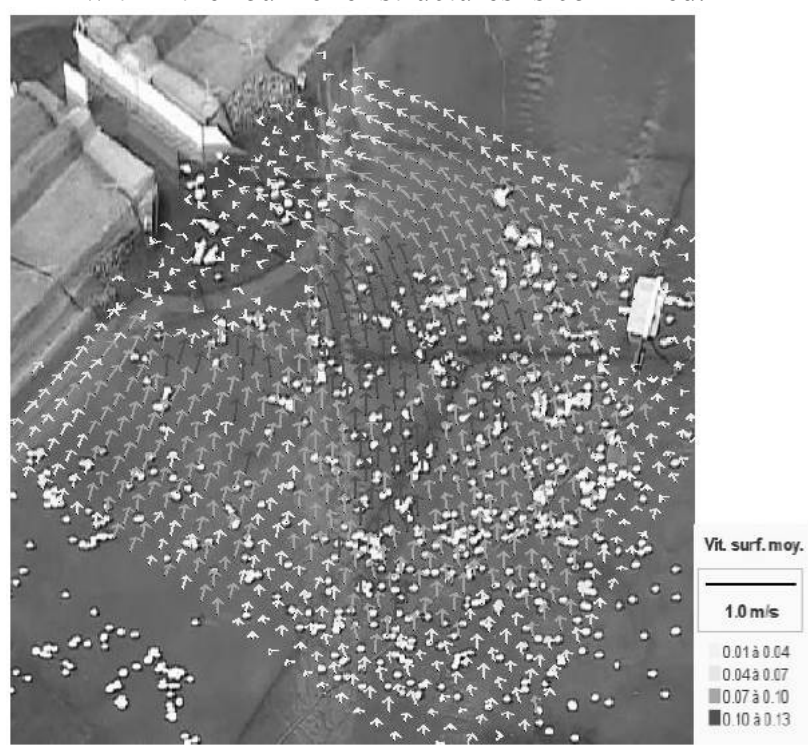

Figure 7. LS-PIV treatment in front of a relief structure (100year flood, current conditions)

\subsection{Tests in design conditions}

In design conditions, i.e. with the CFAL project implemented just upstream of the existing structures, the tests results show that:

- the maximum impact on water levels in the flood plain is noticed upstream from the relief structures (between +10 and $+18 \mathrm{~cm}$ ), and reduces as going upstream (less than $4 \mathrm{~cm}$ at the upstream end of the model),

- the maximum flood extent surveyed on the model is slightly affected by the - moderate rise in water level, only in the flattest areas,

- the project layout reduces the hydraulic capacity of the relief structures $(-13 \%)$, which results in a higher flow in the main channel. 


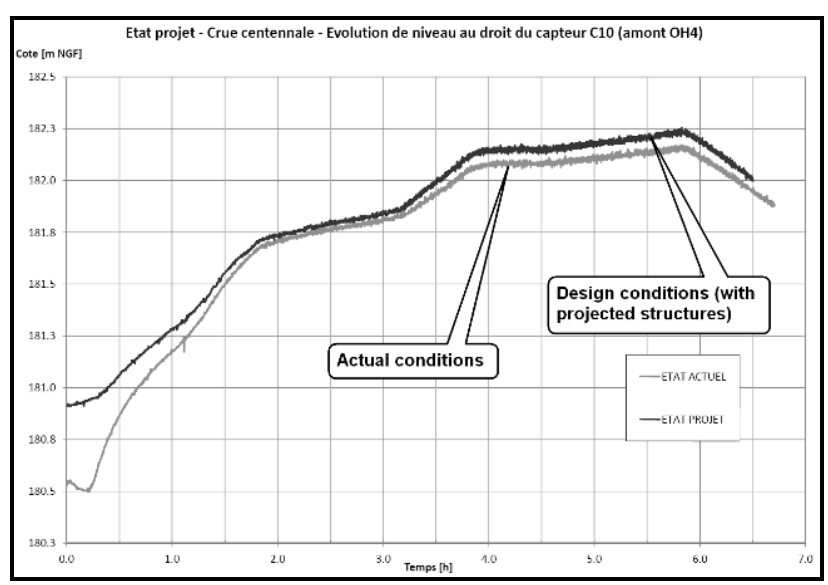

Figure 8. Comparison of water level recording in front of one relief structure (100-year flood)

In addition to the conventional use of dye (fluorescein) to characterise flow patterns, the LS-PIV procedure enable to precisely describe the velocity fields in front of the planned scheme, and thus identify the impact of a given structure. Stream line patterns, flow separation and recirculation areas can be characterised, giving a better understanding of the phenomena involved and thus a precious guide for the optimisations design.

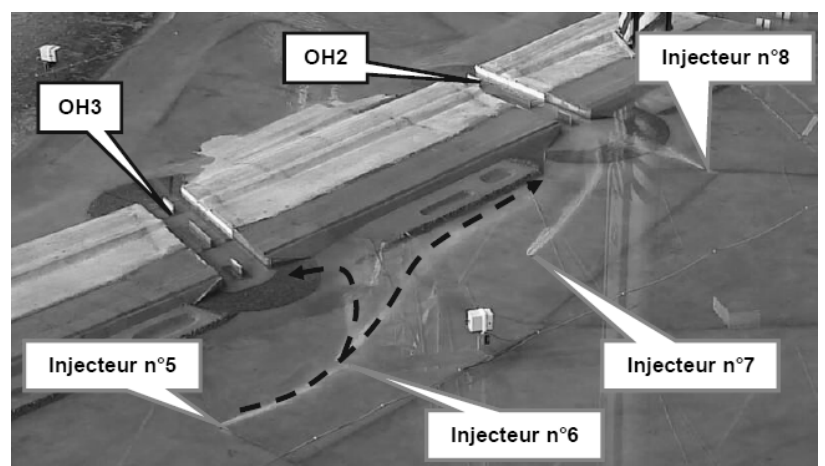

Figure 9. Flow pattern characterisation with dye in front of a relief structure (100-year flood, design conditions)

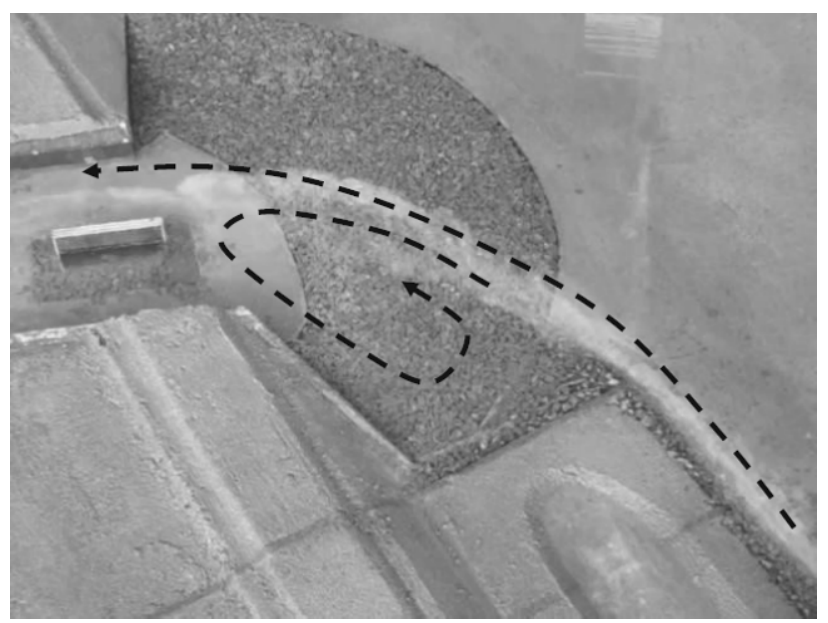

Figure 10. Effect of projected structure on flow pattern close to a relief structure with use of dye (100-year flood, design conditions)

\subsection{Tests in optimised design conditions}

Several optimisations are designed and tested on the physical model:

- lowering of the relief structures inlets to reduce head losses, and partial modification of the embankment shape in the vicinity of the relief structures,

- complete removal of the storm management ponds located at the foot of the main embankment,

- Creation of an outlet channel for one of the relief structures in order to improve its hydraulic functioning.

The first optimisation gives on its own the better results, as the maximum water level recorded during flood peaks are similar to the initial conditions.

The other optimisations do not bring additional significant effect on the flood flow conditions, and therefore do not need to be implemented.

The hydraulic transparency of the global scheme can thus be achieved by means of relatively simple works and minor project's adaptations.

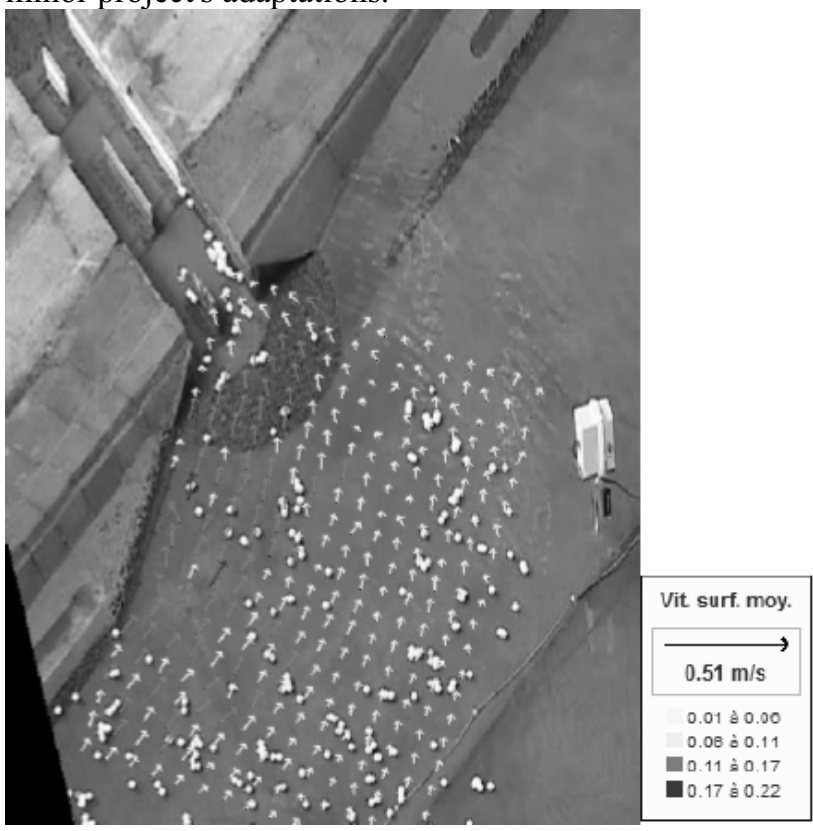

Figure 11. LS-PIV treatment in front of a relief structure after first optimisation (1000-year flood, optimised design conditions)

\section{Conclusions}

The physical scale model enabled to identify the hydraulic impact of the project during flood events (increase of the maximum water level, due to bad flow conditions at the inlet of relief structures) and validate the improvements of the design (reshaping of the relief structures' inlet, and removal of embankments close to the relief structures). The final optimized design ensures the hydraulic transparency of the project.

The scale model is a very useful tool for optimisation of major linear infrastructures crossing flood plain, where flow patterns and functioning of hydraulic structures are not easily accessible by numerical modelling only. 
Indeed, the scale model represents completely and in detail all the structures: embankments, relief structures (walls, inlet and outlet with rip-rap protection, piers), viaducts (shape and orientation of piers), which makes the complete and proper modelling of all head losses possible, when the numerical modelling has to rely on theoretical parameters. The scale model is in this way a unique tool as it gives the opportunity to gain a reliable insight into the flow conditions, as real as it can be in nature. 